\title{
LA LUCHA CONTRA EL TERRORISMO EN LA ESTRATEGIA DE SEGURIDAD NACIONAL 2013
}

\author{
Antonio Alonso ${ }^{1}$ \\ Universidad San Pablo CEU / UNISCI
}

\begin{abstract}
Resumen:
La Estrategia de Seguridad Nacional aprobada en 2013 (ESN/2013) pretende ser un instrumento que sirva de marco para garantizar al máximo la seguridad de España y de los españoles. En el caso concreto del terrorismo, da por derrotada a ETA, señala el yihadismo como el tipo de terrorismo más preocupante pero ignora otros tipos de terrorismo señalados por documentos oficiales del entorno europeo -especialmente por la Europol- como son los lobos solitarios, los ataques perpetrados por la extrema derecha y la extrema izquierda, y los de origen nacionalista, que son los más numerosos en España.
\end{abstract}

Palabras clave: Estrategia de Seguridad Nacional 2013, terrorismo, yihadismo, ETA, lobos solitarios.

Title in English: "The Fight Against Terrorism in the National Security Strategy 2013"

\begin{abstract}
:
The National Security Strategy 2013 is considered a security framework for dealing with threats and risks and aims thus to ensure security for Spain and its citizens. In the specific case of terrorism, it assumes that ETA has been defeated and it mentions jihadism as the most worrisome type of terrorism. But it ignores other kind of terrorism highlighted by European official documents -especially by Europolsuch as lone wolves, the attacks perpetrated by rightist and leftist extremists, and those of nationalist origin, the largest in Spain.
\end{abstract}

Keywords: National Security Strategy 2013, Terrorism, Jihadism, ETA, Lone Wolves.

Copyright $\odot$ UNISCI, 2014.

Las opiniones expresadas en estos artículos son propias de sus autores, y no reflejan necesariamente la opinión de UNISCI. The views expressed in these articles are those of the authors, and do not necessarily reflect the views of UNISCI.

\footnotetext{
${ }^{1}$ El Dr. Antonio Alonso Marcos es profesor del Instituto de Humanidades "Ángel Ayala”, Universidad CEU-San Pablo, investigador senior de UNISCI y miembro del Foro Hispano-Argelino.

Dirección: Instituto de Humanidades “Ángel Ayala”, Universidad CEU San Pablo, Paseo Juan XXIII, 8, 28040, Madrid.

E-mail: aalonso@ceu.es. 


\section{El terrorismo en el actual sistema internacional}

El terrorismo no es más que una táctica, un modus operandi. Sin embargo, se ha tomado la parte por el todo y bajo el paraguas de este término se sitúan hoy grupos que no pertenecen al Estado -que tiene el monopolio de la violencia legítima- y que se dedican a utilizar la violencia para la consecución de objetivos políticos, generalmente basándose en una suerte de ideología más o menos trabada que dé sentido y motivación a las personas que están involucradas en este tipo de actos. Como viene siendo habitual en los grupos situados fuera de la Ley, se da una simbiosis -o directamente una mezcla en ocasiones - entre estos grupos y otros que se dedican exclusivamente a los tráficos ilícitos internacionales -droga, armas, esclavos, blancas, etc- o que están involucrados en actividades de extorsión, blanqueo de capitales o redes mafiosas. Se puede decir que el terrorismo ha perdido definitivamente lo poco que le pudiera quedar de residuo romántico - los famosos freedom fighters - y se ha transformado en una actividad delictiva más sin excusa legitimadora -aunque fuera sólo ante cierto público-.

El terrorismo es un fenómeno que afecta a la seguridad colectiva - no solo a la seguridad de un país- y que se nutre de una serie de elementos globales, no exclusivamente locales. De esta manera, el actual sistema internacional se ha visto afectado por dicho fenómeno y, viceversa, el terrorismo ha ejercido una fuerza dentro de dicho sistema para que este evolucione en un sentido. Si se acepta la decadencia de EE.UU. como poder hegemónico global, se puede apreciar que una de las raíces de dicho decaimiento es el excesivo gasto militar que ha supuesto la lucha global contra el terrorismo (GWoT, por sus siglas en inglés), especialmente las guerras de Afganistán e Irak, pero también otras operaciones en Pakistán y otros países de Oriente Próximo y el norte de África, más conocido como MENA por sus siglas en inglés ${ }^{2}$.

Como en política no existe el vacío de poder, y las Relaciones Internacionales no se abstraen de esta norma general, el hecho de que la Administración Obama se vaya replegando implicaría el ascenso de otra u otras potencias que ocuparían el espacio dejado por los EE.UU. Este parece ser el caso de Rusia -que desde la llegada de Putin al poder no ha cesado de escalar-y, sobre todo, China -que en los últimos veinte años tampoco ha dejado de extender su red de influencias por todo el globo, incluyendo escenarios tan poco asiáticos como el centro de África o el sur de América-, amén de otros países que también desean hacerse un hueco entre los grandes, como por ejemplo Brasil, India o Sudáfrica. La Estrategia Americana lo expresa así: "Economic growth has alleviated poverty and led to new centers of influence. More nations are asserting themselves regionally and globally. The lives of our citizens their safety and prosperity-are more bound than ever to events beyond our borders", ${ }^{\text {. La }}$ pregunta que surge inmediatamente es si estas potencias tomarán el relevo de EE.UU. también en lo que se refiere al control de la seguridad en el ámbito global, esto es, si veremos a China desplegando sus Ejércitos en escenarios alejados de Asia, por poner un ejemplo.

Así como en los tiempos de la Guerra Fría surgieron grupos terroristas que luchaban por la independencia de algunos territorios y cuya acción era aprovechada por las superpotencias

\footnotetext{
${ }^{2}$ Así como surgió una alianza para luchar contra el terrorismo yihadista en cualquier parte del mundo, los yihadistas de Europa también se han organizado para enviar combatientes a los escenarios bélicos citados. Ver los trabajos de Pérez Ventura, Óscar: "Europa exporta 'yihadistas"”, Es Global, 19 de marzo de 2014, en http://www.esglobal.org/La-Lista-Europa-exporta-yihadistas; y también "Mustafá Setmarián, el ideólogo de la yihad moderna", Documento Marco del IEEE, no 5, 24 de marzo de 2014.

${ }^{3}$ Ver: "US National security Strategy", White House (May 2010), at

http://www.whitehouse.gov/sites/default/files/rss_viewer/national_security_strategy.pdf, p.7.
} 
para inclinar el equilibrio de poder en su beneficio, durante los años '90 estos grupos aprovecharon la experiencia adquirida para seguir actuando en otros escenarios de guerra civil y prácticamente desaparecieron. Pero en esos años se estaba gestando el tipo de terrorismo que se haría prácticamente con el monopolio de este tipo de violencia. En efecto, los grupos yihadistas fueron perfeccionando sus técnicas, su modus operandi y sus capacidades logísticas hasta llegar a uno de sus mayores golpes, el 11-S. Lamentablemente, aquella no fue la última vez que este terrorismo golpeó a los ciudadanos sino que a este ataque le siguieron otros muchos contra objetivos occidentales, pero también contra objetivos sunitas o chiitas que hicieran provocaran un deterioro tal de la situación en Irak o Afganistán que se pudiese hablar francamente de guerra civil. Como se ha podido comprobar, uno de los objetivos de estos grupos ha sido intentar desestabilizar la situación en países de Medio Oriente y de África, lo que a su vez traslada la inestabilidad al Mediterráneo y, por ende, a Europa y a los intereses estratégicos de los EE.UU. -no hay que olvidar que desde hace cincuenta años, establecer un corredor seguro entre EE.UU. y el Golfo Pérsico ha sido uno de los objetivos prioritarios de los sucesivos Presidentes estadounidenses-.

Sin lugar a dudas, el terrorismo es una de las mayores preocupaciones también para el Gobierno español. De hecho, es ya una de las amenazas más clásicas ${ }^{4}$, esto es, que suele aparecer en toda enumeración de amenazas. No podía faltar, por tanto, en esta Estrategia de Seguridad Nacional 2013 (ESN/2013) -cuyo capítulo tercero hace un elenco de dichas amenazas- apareciendo en segundo lugar, justo detrás del más tradicional de todos -los conflictos armados-. En efecto, sería impensable en el mundo posterior al 11-S que un país occidental no se dotara de un conjunto coordinado de instrumentos para luchar activa y eficazmente contra el terrorismo. Aunque pueda parecer que 2001 es una fecha muy lejana o que es "agua pasada", nada más lejos de la realidad ya que allí hay que buscar el origen de la presencia norteamericana en Afganistán e Irak y allí hay que buscar las excusas más utilizadas por los yihadistas en sus proclamas antioccidentales. Estos no se suelen retrotraer al pasado colonialista de Europa sino que denuncian el afán imperialista de EE.UU. y le señalan como verdugo de miles de "fieles musulmanes" que sufren el ataque gratuito de "esa fuerza demoniaca".

Y aquí se hace necesario tener en cuenta tres factores de orden internacional. En primer lugar, el origen del terrorismo al que España deberá hacer frente en las próximas décadas no se encuentra en el interior de sus fronteras sino fuera de ellas, incluso en lugares tan remotos como Pakistán o Afganistán ${ }^{5}$. Y en segundo lugar, la respuesta a esta amenaza no puede ser en solitario sino que debe contar con la cooperación de otros actores internacionales, buscando alianzas bilaterales e incluso multilaterales, con Estados o con organizaciones internacionales. En tercer lugar, y muy ligado a los dos aspectos anteriores, España debe tener en cuenta cómo está estructurado el actual sistema internacional y hacia dónde evoluciona ya que no es lo mismo moverse en el mundo bipolar de la Guerra Fría que en el mundo posterior a la caída del muro de Berlín donde la potencia hegemónica o hegemon -EE.UU.— marcaba las pautas de acción, o en el mundo posterior a la guerra de Irak (2003), punto a partir del cual

\footnotetext{
${ }^{4}$ No parece adecuado encuadrar al terrorismo como una nueva amenaza pues el uso de la violencia ilegítima con fines políticos es casi tan antiguo como la propia política.

${ }^{5}$ Es preciso matizar aquí, aunque luego se explicará más adelante, que el terrorismo yihadista es un elemento exógeno pero que en los últimos años ha penetrado en algunos ambientes frecuentados por inmigrantes musulmanes y por lo tanto se ha vuelto también endógeno. En este punto hay que remarcar que el peligro no sólo se encuentra en Ceuta y Melilla sino en cualquier punto del país, como es el preocupante caso de Cataluña. Además, como se verá, se ha excluido prácticamente del análisis al resto de terrorismos -de origen anarquista, de extrema izquierda, de extrema derecha o ultranacionalista - ya que el que está más vivo y activo en España en la actualidad es el yihadista.
} 
el consenso internacional se rompe definitivamente y otras potencias económicas comienzan a exigir sin rubor alguno su papel protagonista en el concierto político global.

Por otro lado, el papel de la UE es -o debería ser- fundamental en la lucha contra el terrorismo, especialmente por dos motivos. El primer motivo es que debe haber mayor coordinación entre las Fuerzas y Cuerpos de Seguridad de los distintos Estados miembros para evitar que la libertad de movimiento de personas, mercancías y capitales se convierta en una ventaja para los terroristas y una desventaja para quienes los persiguen -que carecen de autoridad suficiente para traspasar las fronteras con eficacia y para lo que ya se han puesto en marcha mecanismos para favorecer la cooperación policial y judicial-. Y el segundo motivo estaría, de nuevo, relacionado con la estructura del sistema internacional, esto es, con el protagonismo que puede tener realmente la UE para luchar contra el terrorismo fuera de sus fronteras con instrumentos militares -como en el Sahel- o con políticas de apoyo al desarrollo económico y a la construcción de una sociedad civil -como en la ribera sur del Mediterráneo y en general en los países vecinos de la UE-.

También se ha acudido a medios militares para la lucha contera el terrorismo. ¿Es este el instrumento el adecuado para este tipo de lucha? La respuesta a esta pregunta es peliaguda ya que en la última década se han invertido muchos recursos -humanos, económicos, logísticos, políticos- en esa dirección. Sin embargo, las lecciones aprendidas en la guerra de Indochina parecían haber dejado claro que un actor estatal, por muy poderosos que fuera, no podría salir victorioso $-\mathrm{o}$ al menos no lo tendría nada fácil- frente a un enemigo difuso como es una guerrilla o, como es en este caso, un grupo terrorista. La asimetría en la naturaleza de los grupos enfrentados, que implicaba también una asimetría en los medios usados, en el número de los combatientes, en el apoyo material utilizado, etc llevaba, al final, a una asimetría en la legitimidad o autoridad con la que se enfrentaban ${ }^{6}$. Este tipo de experiencias, que se han visto corroboradas en las guerras prolongadas de Afganistán y de Irak, donde se ganó rápidamente la guerra pero se ha perdido claramente la paz y no se ha sabido garantizar una reconstrucción de sendos países. En palabras de Félix Arteaga:

"En lugar de enfrentarse a ejércitos regulares, las fuerzas armadas occidentales se han venido enfrentando con actores no estatales violentos que se organizan en insurgencias en forma de guerrilla, grupos terroristas o criminales y que combaten de manera asimétrica, sin restricciones morales ni jurídicas ${ }^{7}$.

Si la amenaza del terrorismo para España proviene del Sahel, como se afirma desde la UE, no se pude luchar exclusiva ni principalmente con medios militares. Si la amenaza es el terrorismo yihadista -especialmente presente en Ceuta, Melilla y Cataluña- el empleo de instrumentos militares tiene menos sentido aún. Menos todavía si se trata del terrorismo etarra. Parece bastante claro que las medidas apropiadas son las políticas, ya que buscan separar a ese grupúsculo de la porción de la sociedad a la que pretende representar ${ }^{8}$, dejarles

\footnotetext{
${ }^{6}$ Ver: Arreguín-Toft, Ivan: "How the Weak Win Wars. A Theory of Asymmetric Conflict", International Security, vol 26, no 1 (verano de 2001), pp. 93-94.

${ }^{7}$ Ver: Arteaga, Félix (coord.): "La Defensa que viene. Criterios para la reestructuración de la Defensa en España", Elcano Policy Paper, no 3 (Octubre 2013), p. 10.

${ }^{8}$ Ver Spalek, Basia (ed.) (2012): Counter-Terrorism: Community-Based Approaches to Preventing Terror Crime. Palgrave Macmillan, Nueva York.
} 
aislados y deslegitimados de tal manera que, perdiendo todo apoyo social, deslegitimadas sus posturas ideológicas, no tengan más remedio que abandonar la lucha armada ${ }^{9}$.

La lucha contra las guerrillas o contra los insurgentes dejaron bien asentados tres axiomas: 1) El poder relativo explica los intereses relativos; 2) Los intereses relativos explican la relativa vulnerabilidad política; y 3) La relativa vulnerabilidad explica por qué los actores fuertes pierden ${ }^{10}$. Estas lecciones deben ser tenidas en cuenta en la lucha antiterrorista.

La ESN/2013 también habla de "potenciadores" o "multiplicadores", factores que hacen que estas amenazas puedan hacerse realidad, sean más probables o se lancen con más fuerza contra su objetivo. En el caso del terrorismo, parece bastante evidente que dichos potenciadores -pobreza, desigualdad y extremismos, entre otros- se encuentran en el origen de dicho fenómeno.

Lo que parece evidente a todas luces es que la lucha contra el terrorismo no es nada sencillo y que, en opinión de muchas voces autorizadas, Occidente está perdiendo la guerra contra el terrorismo ${ }^{11}$.

Por último, hablando de la vigencia de la GWoT, se puede concluir con Félix Arteaga que:

"las expectativas no han evolucionado como se esperaba, por razones de eficacia y legitimidad. Las grandes organizaciones de seguridad internacionales encuentran dificultades para actuar debido a las divergencias entre los intereses y culturas estratégicas de sus miembros, así como a la desigual distribución de cargas y responsabilidades entre ellos ${ }^{12 "}$.

\section{El papel de la Unión Europea}

La UE también ha ido dotándose con el paso del tiempo de instrumentos legales y de medidas para luchar eficazmente contra el terrorismo y su financiación. Además, la norma que sirve de referencia para este asunto, la Decisión Marco 2002/745/JAI, hace hincapié en un asunto de vital importancia para todo terrorismo pero muy especialmente para el islamista: la captación y entrenamiento de nuevos miembros. Esta normativa entiende que -de manera muy similar, aunque más amplia, a la legislación española - el terrorismo tiene como finalidad:

1) intimidar gravemente a una población;

\footnotetext{
${ }^{9}$ Ver Aznar Fernández de Montesinos, Federico: “Terrorismo y estrategia asimétrica”, Documento de Opinión del IEEE, no 9 (Enero 2011); ver especialmente, del mismo autor, "Reflexiones sobre el empleo de las Fuerzas Armadas en la lucha contra el terrorismo local”, Documento de Análisis del IEEE, nº 12 (Febrero 2014). En este último se recoge la famosa frase de T.E. Lawrence: "hacer la guerra contra los insurgentes es tan caótico y lento como comer sopa con un cuchillo"; Ver Lawrence, Thomas E. (2000): Los siete pilares de la sabiduría, Óptima, Barcelona, p. 154.

${ }^{10}$ Ver: Mack, Andrew J.R.: "Why Big Nations Lose Small Wars: The Politics of Asymmetric Conflict," World Politics, vol. 27, no 2 (Enero 1975), pp. 175-200.

${ }^{11}$ Ver Rogers, Paul (2007): Why We're Losing the War on Terror, Polity, Cambridge; del mismo autor, ver: (2010): Losing Control: Global Security in the 21 st Century, $3^{\mathrm{a}}$ ed., Pluto Press, Londres.

${ }^{12}$ Ver Arteaga, Félix (coord.): "La Defensa que viene. Criterios para la reestructuración de la Defensa en España”, Elcano Policy Paper, no 3, Octubre 2013, p. 11.
} 
2) obligar indebidamente a los poderes públicos o a una organización internacional a realizar un acto o a abstenerse de hacerlo; o

3) desestabilizar gravemente o destruir las estructuras fundamentales políticas, constitucionales, económicas o sociales de un país o de una organización internacional ${ }^{13}$.

Además de esta Decisión Marco, existen otros muchos instrumentos, órganos e instituciones que se dedican a la lucha contra el terrorismo. De entre los instrumentos destacan varias Estrategias, Planes de Acción y Programas (OISIN I y II, Estocolmo y La Haya). Entre las instituciones están el Comité Permanente de Cooperación Operativa en materia de seguridad interior, la Oficina Europea de Policía-Europol (desde el 1 de enero de 2010), la Eurojust, la Red Judicial Europea, la Escuela Europea de Policía (CEPOL) y la Agencia Europea para la gestión de las fronteras exteriores (Frontex). Más adelante se volverá sobre la Europol y sus instrumentos más específicos en la lucha contra el terrorismo.

La Estrategia de lucha contra el terrorismo de la $U E^{14}$, tiene como compromiso estratégico "luchar contra el terrorismo de forma global, al tiempo que se respetan los derechos humanos y se crea una Europa más segura, que permita a sus ciudadanos vivir en un espacio de libertad, seguridad y justicia". Como se puede apreciar, ya en 2005 -año del documento- se está señalando implícitamente la diferencia de la lucha antiterrorista europea frente a la guerra contra el terror estadounidense; en el caso europeo, el límite está puesto en el respeto a los derechos humanos, por lo que la UE será más timorata a la hora de combatir esta lacra en sus países de procedencia, siendo las medidas propuestas más de tipo económico que bélico ${ }^{15}$. El debate queda abierto si ese tipo de políticas que han buscado fomentar el desarrollo económico del norte de África ha servido realmente para frenar el avance del yihadismo o simplemente ha servido de ayuda -involuntaria, por supuesto- para que esas redes se pudieran beneficiar de alguna manera de dichas ayudas, generando así un perverso efecto no deseado de la Política Europea de Vecindad (PEV). Así, la UE profundiza en la filosofía del Consejo Europeo de Tampere (1999) ${ }^{16}$ en la que se concibe a la UE como una isla de prosperidad económica en medio de un entorno problemático y que debe ser defendida como una fortaleza, imposible de penetrar excepto si se tiene salvoconducto; aunque parezca que la PEV rompe con esta forma de concebir a la UE al ofrecer ayudas a los países del entorno, lo que hace en realidad es rodearse de Estados tapón que separen la desarrollada Europa del subdesarrollado sur.

Aparte de estas medidas de tipo económico, la UE considera que entre sus prioridades clave para prevenir el terrorismo están: "Desarrollar el diálogo intercultural dentro y fuera de la Unión" y "Desarrollar un vocabulario no emotivo para debatir las cuestiones". Aquí se parte de una premisa errada: los gobiernos no europeos son tan laicos como los de la UE. Eso no existe. Menos aún si miramos a sus sociedades. La idea de la separación neta entre Iglesia y Estado es una cuestión que lleva desarrollándose en Europa desde hace poco más de dos siglos - desde la Ilustración- y que aún produce disfunciones en el funcionamiento interno de los miembros de la UE; cuánto más en países de raíz islámica donde religión y política van unidas desde el mismo origen del Islam - no hay que olvidar que Mahoma fue caudillo

\footnotetext{
${ }^{13}$ Ver la Decisión Marco 2002/745/JAI.

${ }^{14}$ Ver: http://europa.eu/legislation_summaries/justice_freedom_security/fight_against_terrorism/133275_es.htm.

${ }^{15} \mathrm{La}$ ruptura del consenso internacional en lo que se refiere a la lucha antiterrorista ya estaba consumada. En el caso español esto se vio de manera más rotunda con la retirada unilateral de tropas de Irak decidida en abril de 2004 y con la llamada del Presidente Zapatero a otros países a que siguieran su ejemplo.

${ }^{16}$ Ver http://www.europarl.europa.eu/summits/tam_es.htm.
} 
político-militar a la par que profeta-. El diálogo que se pueda establecer entre culturas que se sitúan en planos distintos en lo que se refiere al hecho religioso y cómo éste debe afectar o no al orden político-social, dará, como es lógico, escasos resultados. De hecho, el escepticismo es la postura más compartida por los expertos en estas cuestiones ${ }^{17}$.

Retomando la cuestión de Europol, el mismo organismo reconoció que la naturaleza transnacional de las amenazas a las que tiene que hacer frente a diario -entre las que se encuentra el terrorismo- hace que se tengan que replantear el papel de Europol y sus capacidades, reclamando una mayor cooperación por parte de los Estados miembro.

Comentando el Informe de Situación de Europol del 2011, el Coordinador de la UE para la lucha antiterrorista le dice al Consejo de la UE que la muerte de Bin Laden supuso un duro golpe simbólico pero que no se puede caer en la autocomplacencia pues dicha amenaza sigue siendo significativa y se está transformando, de manera que algunos nacionales de la UE están viajando a zonas de conflicto para entrenarse allí y algunos se están uniendo a grupos terroristas en Afganistán o Somalia ${ }^{18}$. El mismo Informe alaba el trabajo del gobierno español a la hora de dar una preparación a imanes que ya están en activo o que pueden pasar a estarlo, evitando que tengan que viajar a otros países a recibir instrucción religiosa -con el peligro que eso entrañaría de verse envueltos en procesos de radicalización ${ }^{19}$.

Por otro lado, el Consejo de la UE señala que se está asistiendo a dos fenómenos preocupantes: los terroristas solitarios y el surgimiento de "santuarios" fuera de la UE ${ }^{20}$. Más concretamente, la UE se preocupa no tanto por Al Qaeda central - "core Al Qaeda"-sino por sus filiales y franquicias en la Península Arábiga o en el Magreb Islámico, que se están haciendo fuertes en Libia y en otros lugares gracias a sus vínculos con Boko Haram y $\mathrm{Al}$ Shabab. No obstante, el terrorismo proveniente de grupos de la extrema derecha también tienen preocupadas a las autoridades europeas ${ }^{21}$.

La Estrategia Europea viene complementada por un Plan de Acción publicado en 2007. En él se detallan una serie de medidas muy interesantes para prevenir, proteger, perseguir y responder la amenaza terrorista. Entre estas resalta una orientada a potenciar las voces no intolerantes dentro del mundo musulmán o el apoyo al desarrollo político y económico.

El Programa de Estocolmo hace hincapié en el respeto a los derechos humanos en la lucha contra el terrorismo ${ }^{22}$, sobre todo "para que no susciten oposición". Además, "todas las partes interesadas deberían evitar estigmatizar a un colectivo específico de personas y deberían desarrollar el diálogo intercultural para promover el conocimiento y la comprensión mutuos", algo bastante difícil en este mundo globalizado donde, gracias a la cada vez más creciente inmediatez de la información, se corren más riesgos de incomprensión -como pusieron de manifiesto los episodios de las caricaturas de Mahoma y el discurso de Benedicto XVI en Ratisbona-.

\footnotetext{
${ }^{17}$ Ver Renard, Thomas: "Confidential partnerships? The EU, its strategic partners and international terrorism", ESPO Working Paper, no 4 (Enero 2014), en http://www.fride.org/descarga/WP4 Confidential_partnerships.pdf.

${ }^{18}$ Ver: "Informe del Consejo de la UE 17594/11" (25 de noviembre de 2011), p. 2.

${ }^{19}$ Ibid., p. 5.

${ }^{20}$ Ver: "EU Counter-Terrorism Strategy - Discussion paper 2012", 9990/2012 (23 de mayo de 2012), p. 1.

${ }^{21}$ Ver: "EU Counter-Terrorism Strategy - Discussion paper 2011", 17595/1 (28 de noviembre de 2011), p. 1.

${ }^{22}$ Ver: "Programa de Estocolmo — una Europa abierta y segura que sirva y proteja al ciudadano" (2010/C 115/01), p. 24; también es esclarecedor el "Second Report on the implementation of the EU Internal Security Strategy", COM(2013) 179 final (10 de abril de 2013).
} 


\section{3. Éxitos y fracasos de la Estrategia Española de Seguridad 2011}

La Estrategia Española de Seguridad 2011 (EES/2011) no fue un documento de consenso, no supo sumar esfuerzos de la mayoría del arco parlamentario ni supo entrar en diálogo con amplios sectores de la sociedad que podrían haber aportado su punto de vista y su experiencia. Esa es la característica más sobresaliente de dicho documento, al menos a la luz del nacimiento de una nueva estrategia apenas dos años más tarde, cuando precisamente uno de los rasgos más definitorios de una estrategia es su visión a largo plazo.

No obstante, hay que señalar que las diferencias entre ambos documentos no son tan profundas -en lo que a terrorismo se refiere- debido en gran medida a que en esta última ocasión sí se buscó el diálogo, reflejo de un cambio de actitud en lo que se refiere a las denominadas tradicionalmente "políticas de Estado", llamadas a no variar drásticamente de legislatura en legislatura ni a estar sujetas al vaivén de los cambios políticos.

La EES/2011 señalaba que el terrorismo "amenaza directamente la seguridad de todos los ciudadanos, pretende socavar las instituciones democráticas y puede llegar a causar graves daños en nuestras infraestructuras críticas en un momento determinado, ${ }^{, 23}$. Con esto se señala qué es lo que se pretende defender y frente a quién, faltando el cómo. Aquí, el concepto de seguridad ya no pone el énfasis en la defensa del territorio sino en la vida de las personas y en su estilo de vida -como se enfatiza en prácticamente todas las estrategias de seguridad de nuestro entorno-, siendo uno de sus núcleos fundamentales la defensa de las instituciones democráticas, garantes de las libertades públicas de las que disfrutan sus ciudadanos, y las así llamadas "infraestructuras críticas", que nos e reducen sólo a presas o plantas energéticas, sino a todo un entramado que sostiene de manera casi milagrosa nuestro complejo modo de vivir, muy lejano de aquella bucólica vida campesina de siglos pasados. Por eso, con toda lógica, la EES/2011 plantea que, entre otros, "sus ejes son la anticipación, la prevención, la protección, y la disponibilidad de los medios" 24 .

El Código Penal español define el terrorismo como aquellos actos que "tengan por finalidad o por objeto subvertir el orden constitucional o alterar gravemente la paz pública mediante la perpetración de cualquiera de los delitos previstos en la Sección siguiente" (art. 571.3). Es contra este tipo de actos que el Estado quiere defenderse. Si bien es cierto el terrorismo puede entenderse de manera mucho más general simplemente como una táctica, es decir, como un método de lucha armada, que por lo tanto también puede -en el sentido de posibilidad, no de permiso - ser empleado por guerrillas o incluso por ejércitos regulares. Pero volviendo al concepto más ampliamente admitido de terrorismo, este viene realizado por grupos cuya finalidad es sembrar el terror y subvertir así el orden político establecido.

Tanto la EES/2011 como la ESN/2013 son documentos esquemáticos, que describen de manera general la situación y la forma de afrontarla. Sin embargo, a pesar de su simplicidad, toca muchos temas, de manera que introduce, casi sin querer, casi todos los aspectos de la vida ordinaria en la agenda de seguridad, lo cual tiene sus ventajas y sus problemas. Por un lado, es cierto que securitizar un asunto parece que le da más relieve y le hace aparecer como prioritario, pero por otro se corre el riesgo de que securitizando cualquier tema de la agenda política se pierda el sentido auténtico de la propia seguridad ${ }^{25}$. Esto nos lleva a otro asunto de gran calado: ¿quién es el responsable de proteger la seguridad en los medios de transporte,

\footnotetext{
${ }^{23}$ Ver: "Estrategia Española de Seguridad" (2011), p. 11.

${ }^{24}$ Ibid., Idem.

${ }^{25}$ Ver Sheehan, Michael (2005): International Security: An Analytical Survey, Londres, Lynne Rienner, pp. 6062.
} 
como los trenes? ¿Quién debe encargarse de vigilar los edificios públicos, como las escuelas? ¿Y los lugares de ocio, como los restaurantes? En todos estos lugares citados ha habido atentados terroristas. Y, como se puede intuir, es prácticamente imposible vigilar cada uno de dichos lugares, por lo que para frenar el terrorismo hay que ir a la raíz, no a los lugares donde se manifiesta, sino allí donde se origina, donde nace y se hace fuerte.

Para eso se creó por Acuerdo del Consejo de Ministros del 28 de mayo de 2004 el Centro Nacional de Coordinación Antiterrorista (CNCA), cuya finalidad esencial es, como su propio nombre indica, coordinar la lucha antiterrorista de las Fuerzas y Cuerpos de Seguridad del Estado -Policía Nacional, Guardia Civil y CNI-, principalmente en lo que se refiere a compartir información general sobre los grupos terroristas que operan en España. Si en 2004 ETA estaba aún entre sus prioridades, la EES/2011 la relega a un segundo plano -"la madurez y unidad de la sociedad española y la eficacia policial y judicial nos han llevado a un momento en el que el final de ETA está más cerca que nunca"- y la ESN/2013 la da ya por acabada con un párrafo similar al de la EES/2011 -"La fortaleza del Estado de Derecho, la solidez de sus instituciones y la eficacia de las acciones implementadas han derrotado a ETA" ${ }^{26}$ -

Tras los atentados del 11-S EE.UU. hizo un examen de conciencia y se dio cuenta de que uno de sus mayores fallos de inteligencia había sido la falta de inteligencia humana (HUMINT), carencia que había intentado suplir con tecnología; gran lección, aunque costosa: el agente sobre el terreno o infiltrado es un elemento esencial e irremplazable. España, que desde junio de 2001 se había beneficiado del servicio de la red ECHELON, no pudo o no supo adelantarse a los terroristas aquel 11-M de 2004 y fue a partir de ese año que puso a disposición de las Fuerzas y Cuerpos de Seguridad más medios para luchar contra el terrorismo, más enfocado desde entonces hacia el de tipo yihadista. El sistema SITEL, implantado, por lo menos desde el 2001, ha prestado sus servicios a la hora de realizar escuchas telefónicas de yihadistas que estaban próximos a realizar actos terroristas. Como es lógico, no bastaba sólo con invertir recursos en escuchar sino que ha hecho falta contratar nuevo personal experto en los dialectos específicos en que se comunican estas personas y expertos en este tipo de terrorismo.

Aparte de lo ya expuesto, la EES/2011 es un documento que acierta en la teoría de los problemas que existen y de lo que hay que hacer para resolverlos. Señala al terrorismo yihadista como amenaza de gran preocupación, aunque reconociendo que no es lo suficientemente fuerte como para subvertir el orden constitucional. Señala además que hay que luchar contra el mismo en el ámbito nacional, en el europeo -por las especificidades que se han señalado anteriormente- y en el internacional -por lo señalado también en la Introducción- También se autoimpone una serie de límites que, es importante señalarlo, separa a los Estados de los grupos terroristas: no utilizan cualquier arma o instrumento para acabar con el enemigo, sino que se ve limitado por su "respeto a los valores democráticos, los

\footnotetext{
${ }^{26}$ Ver "Estrategia de Seguridad Nacional" (2013), p. 25. El análisis de este párrafo es curioso pues hace una mención expresa a "las víctimas como referencia ética" de la sociedad española en un momento en el que gran parte del electorado del PP "sospechaba" que los gobiernos de Zapatero han dialogado y pactado con la banda una hoja de ruta para poner un fin más o menos pacífico al terrorismo de ETA, y que dicha estrategia ha sido heredada y asumida por actual Gobierno de Rajoy, traicionando de esta manera a su propio electorado. Esa asunción de la estrategia del Presidente Zapatero ha tenido como principal víctima, valga la redundancia, a las propias víctimas de ETA, que han tenido que soportar cómo sus verdugos salen a la calle y colocan en las instituciones democráticas a sus representantes políticos; todo esto sin ninguna pedagogía por parte de los gobiernos del PSOE y del PP que podrían haber explicado estos pasos mucho mejor a la ciudadanía o someterlos a juicio popular, con transparencia, sin ocultar los verdaderos planes.
} 
derechos humanos y el Estado de Derecho". Así como los Ejércitos se ven constreñidos por unas rules of engagement (RoE) muy estrictas en algunos casos pero que aseguran que la lucha se desarrolla según el ius in bellum, las Fuerzas de Seguridad deben someterse al imperio de la Ley, sobre todo para no cae en el lado de los delincuentes y ser así íntegros protectores de esta sociedad.

\section{El terrorismo que nos amenaza}

Siguiendo el esquema del Informe de Situación 2013 de Europol sobre el terrorismo en Europa, se puede clasificar el terrorismo que actualmente sufre España en las siguientes categorías: de inspiración religiosa; el etno-nacionalista y separatista; el de extrema izquierda y anarquista; el de extrema derecha; y, por último, el de los llamados "lobos solitarios" o terrorismo individual. Sin lugar a dudas, el terrorismo que más centra la atención de Europol es el de inspiración religiosa, eufemismo que en realidad hace referencia al de raíz islamista, es decir, el terrorismo yihadista. No obstante, según los datos del mismo informe, el terrorismo más activo fue el separatista -167 ataques de un total de $219^{27}$-, siendo Francia con 121 ataques - y España - con 46- los más afectados. Si atendemos al número de $\operatorname{detenidos}^{28}$, también es el terrorismo separatista el que lleva la delantera -con 257 detenidos - con respecto al de origen religioso - con 159-. Al hilo de lo que se comentaba en el párrafo anterior, aunque muchos líderes religiosos han afirmado en multitud de ocasiones que la religión no debe tomarse como excusa para cometer actos terroristas ${ }^{29}$, lo cierto es que las condenas contra los atentados islamistas no es tan clara y contundente como se desearía.

Sin embargo, la ESN/2013 parte de la premisa de que "la fortaleza del Estado de derecho, la solidez de sus instituciones y la eficacia de las acciones implementadas han derrotado a ETA" -aunque afirma a renglón seguido que habrá que esperar aún a "la disolución de la banda terrorista"es el de raíz islamista. Como se verá, esto es cierto pero sólo a medias.

\subsection{ETA}

¿Está realmente ETA derrotada? Desde el Ministerio del Interior se viene respondiendo afirmativamente a esta pregunta desde la pasada legislatura. Se dice que ETA está acabada operativamente, que sólo hace falta gestionar el final de la banda. Por poner un símil, se está asistiendo al entierro del cadáver pero ahora toca repartir la herencia. Dicho con palabras de varios líderes de distinta sensibilidad política "ahora toca ocuparse de la narrativa", esto es, del relato, de establecer una neta separación entre "buenos y malos", entre víctimas y asesinos,... o bien repartir las culpas entre todos y afirmar que hubo desatinos por parte de ambos lados.

\footnotetext{
${ }^{27}$ Ver el TE-SAT 2013 - EU Terrorism Situation and Trend Report, en https://www.europol.europa.eu/content/te-sat-2013-eu-terrorism-situation-and-trend-report, p. 42.

${ }^{28}$ Ibid., p. 43.

${ }^{29}$ Entre otros, ver las reuniones a más alto nivel entre Iglesia Católica y muftíes musulmanes. Ver también las declaraciones de la Santa Sede o del Consejo Mundial de las Iglesias al respecto. Por último, ver las declaraciones de los líderes religiosos reunidos en el Congreso de las Religiones Mundiales y Tradicionales que se reúnen en Kazajstán auspiciados por el Presidente Nazarbáyev.
} 
Se aduce como prueba principal que ETA dejó de matar en marzo de $2010^{30}$ y que ya no se cobra el denominado "impuesto revolucionario". Además, el 20 de octubre de 2011 ETA anunció el cese definitivo de la violencia. Según distintas fuentes de Interior, con eso basta para asegurar que ETA está derrotada. Se aduce, además, que el mundo etarra está muy dividido y que existe un enfrentamiento extremo entre los partidarios de continuar la lucha armada y los que apuestan por la vía política, y que tal pugna llevará al debilitamiento interno de ese mundo que ha estado tan cerrado y en el que sólo ahora se ha podido abrir una brecha.

Este tono triunfalista contrasta con dos cuestiones que hay que tener en cuenta. La primera y más evidente es que afirmar de manera categórica está derrotada es un error pues puede que en un futuro no muy lejana salga una especie de "ETA-Auténtica" tal y como surgió en Irlanda del Norte un IRA-Auténtico; haber puesto por escrito que ya se ha vencido dejará con las vergüenzas al aire a quien haya afirmado esto y haya en un futuro no muy lejano un atentado terrorista -iojalá que no! - con o sin víctimas mortales. No se pueden mezclar los deseos más profundos -“ojalá que la banda no vuelva a matar" - con la realidad o con una previsión futurible de la actuación de una banda de criminales.

La segunda cuestión, más difícil de ver, no aceptada por todos, es que ETA ya ha triunfado pues el Estado democrático le ha pagado un precio político al aceptar una izquierda abertzale en el Congreso de los Diputados de España y en las instituciones vascas; es decir, han alcanzado una serie de objetivos políticos gracias a la insistencia de su lucha armada. Este segundo punto, más discutido entre la opinión pública española, tiene sus detractores que afirman que no se ha pagado precio político alguno, y que simplemente en esto consiste la democracia, en que un partido político se presenta a unas elecciones democráticas limpias y hay ciudadanos que les votan; en democracia, no se puede criminalizar una ideología. Este último argumento es muy distinto al que se esgrimió en el año 2002 para aprobar la Ley de Partidos $^{31}$ y crear la Sala del 61 de la Audiencia Nacional que con tanto trabajo y esmero acumuló pruebas que demostraron fehacientemente que ETA y Batasuna eran lo mismo, que Batasuna era simplemente la marca política de la banda terrorista. Ahora parece que Bildu o Sortu no son tales marcas políticas, que son cosas radicalmente separadas.

Al hilo de esto último, surgen diversas preguntas en torno a la negociación Gobiernobanda terrorista ${ }^{32}$, no sólo circunscrita al caso etarra sino planteada de manera general. ¿Puede un Gobierno democrático negociar con un grupo terrorista? ¿Qué implicaciones morales tendría eso? ¿Debería hacerlo? ¿Pueden al menos dialogar, sin llegar a negociar? No sería la primera vez que un Gobierno lo hiciera por más que se hubiera hartado de repetir por activa y por pasiva la manida frase de que "este Estado no negocia con terroristas". Así sucedió en Reino Unido, o en el caso aún más llamativo de Israel con Hezbolá, con quien intercambió

\footnotetext{
${ }^{30}$ El 16 de marzo de 2010 ETA mató en el sur de Francia a Jean-Serge Nérin, un gendarme francés, que cayó muerto resultado de un tiroteo con miembros de la banda terrorista, no siendo por tanto un atentado premeditado. El que sí fue el último atentado planificado fue el que segó la vida de dos miembros de la Guardia Civil, Carlos Sáenz de Tejada y Diego Salvá, en la localidad de Calviá (Mallorca) con el método de la bomba lapa colocada en un automóvil; Ver: "El último atentado mortal de ETA fue en marzo de 2010 con el asesinato de un policía francés", RTVE, 20 de octubre de 2010, en http://www.rtve.es/noticias/20111020/eta-no-comete-ningunatentado-mortal-desde-marzo-2010/469100.shtml.

31 “1. Una Sala formada por el Presidente del Tribunal Supremo, los Presidentes de Sala y el Magistrado más antiguo y el más moderno de cada una de ellas conocerá: [...] $6^{\circ}$ De los procesos de declaración de ilegalidad y consecuente disolución de los partidos políticos, conforme a lo dispuesto en la Ley Orgánica 6/2002, de 27 de junio, de Partidos Políticos (LO 6/2002)”. Art. 61 de la LOPJ (LO 6/1985).

${ }^{32}$ Ver: García, Javier Ignacio: “El final de ETA: ¿lucha contra el terrorismo o resolución de conflicto?”, UNISCI Discussion Papers, $\mathrm{n}^{\circ} 13$ (Enero 2007), en

http://revistas.ucm.es/index.php/UNIS/article/viewFile/UNIS0707130009A/27979, especialmente las pp.14-15.
} 
cinco prisioneros de dicha milicia libanesa a cambio de recuperar los cadáveres de dos soldados israelíes ${ }^{33}$, o la negociación de Israel con Hamás por el que se liberó a más de mil presos vinculados con el terrorismo a cambio de un soldado israelí que llevaba secuestrado cinco años ${ }^{34}$.

Y ya, en el caso concreto de ETA, ¿abrió el Presidente Zapatero un proceso de negociación con ETA? Si lo abrió, ¿lo ha continuado el Gobierno de Rajoy? La presencia de Bildu y Sortu en las instituciones democráticas, ¿es parte del pago público de la negociación secreta? El episodio del bar Faisán, ¿fue parte de dicho proceso negociador? El acercamiento de presos de ETA a las cárceles del País Vasco - vieja reivindicación del entorno etarra- ¿es moneda de cambio con la banda? La aplicación de la sentencia de Estrasburgo contra la doctrina Parot, ¿es una pieza más del susodicho proceso? Sea cual sea la respuesta a todas estos interrogantes, parece claro que la ESN/2013 no puede dar por enterrada a ETA... al menos no antes de tiempo. La Estrategia británica no lo hizo en su momento ${ }^{35}$ y no parece recomendable hacerlo en el caso de ETA; la experiencia propia y ajena asegura que poner punto final a la historia de un grupo terrorista no es tan sencillo. Así como se filtraron a la prensa documentos de servicios de inteligencia de otros países que parecían alertar a los servicios españoles de que existía un riesgo cierto e inminente de atentado terrorista yihadista en redes de transporte masivo antes del 11-M -dejando en evidencia a los políticos gestores de la seguridad nacional- así tampoco debería soslayarse el peligro cierto de que algunos miembros de ETA en activo no abandonen tan fácilmente la lucha armada.

De la experiencia de la lucha contra ETA sí se pueden tomar varios elementos que ayudaron en su momento: la creación de la "orden de detención europea", la denominada "euro orden" -adoptada por el Consejo Europeo de junio de 2002- y la profundización en la cooperación internacional $^{36}$ en lo que se refiere a compartir información -especialmente con la ayuda de la red ECHELON ${ }^{37}$ - y la desaparición del santuario ${ }^{38}$ francés -algo que costó

\footnotetext{
${ }^{33}$ Ver: "Culmina el canje de cadáveres y prisioneros entre Israel y Hezbolá", Europasur, 16 julio 2008, en http://www.europasur.es/article/mundo/181801/culmina/canje/cadaveres/y/prisioneros/entre/israel/y/hezbola.htm $\frac{1}{3}$.

${ }^{34}$ Ver: "Mil prisioneros palestinos por un soldado israelí, las claves del intercambio", $B B C, 17$ octubre 2011, en http://www.bbc.co.uk/mundo/noticias/2011/10/111017_soldado_shalit_palestinos_israel_claves_rg.shtml.

35 "At home there remains a serious and persistent threat from residual terrorist groups linked to Northern Ireland. Although these groups have no coherent political agenda and lack popular support, the frequency of terrorist incidents has increased over the last 18 months". Ver: "A Strong Britain in an Age of Uncertainty: The National Security Strategy" (2010), p. 14.

${ }^{36}$ Una muestra de esta cooperación se puede ver en el caso de la desarticulación de una célula yihadista con la colaboración de España, Marruecos y el FBI estadounidense; una operación puesta en marcha desde 2010 por el juez Ismael Moreno y gracias a la cual se detuvo a Mustafa Maya Amaya -líder e ideólogo del grupo-, Paul Cadic y Farik Cheikh -estos dos últimos, franceses que ya estaban listos para marchar a Siria—, Tarik Ahnin, Soufian el Moumni, Mohamed Karraz - estos tres últimos, detenidos en Marruecos— y a Chafik Jalel Ben Amara Elmedjeri -tunecino afincado en España desde hace dos décadas-. "La trama española fue prácticamente desmantelada por las Fuerzas y Cuerpos de la Seguridad del Estado en la operación Cesto, una actuación policial coordinada entre Francia y Bélgica. Esta red ha podido trasladar a Siria no menos de 600 muyahidin, un centenar desde España y el resto desde Marruecos". Ver: Lázaro, Fernando: "Policías marroquíes participan por primera vez en España en un dispositivo contra el yihadismo", El Mundo, 14 de marzo de 2014, en http://www.elmundo.es/espana/2014/03/14/5322aaf6268e3ed77b8b456a.html, accedido el 14 de marzo de 2014.

37 Ver: Ramonet, Ignacio: “¡Todos fichados!”, Le Monde Diplomatique, n 213, Julio 2013, en
} http://www.mondediplomatique.es/?url=editorial/0000856412872168186811102294251000/editorial/?articulo=3c96f3fa-45de4cb1-a3d5-3a3d2e54720c.

${ }^{38}$ En muchas ocasiones, el terrorismo se aprovecha de las diferencias o enemistades entre Estados para lograr sus propios fines. El caso de ETA en Francia es similar al del terrorismo yihadista en Marruecos: "No deja de ser 
décadas de esfuerzos diplomáticos para convencer a las autoridades francesas de que ETA no era un grupo separatista que representaba la lucha de la liberación del pueblo vasco sino que era un mero grupo terrorista, quizás como revancha por el apoyo español a la independencia argelina-.

\subsection{Terrorismo yihadista}

No obstante, es cierto que el tipo de terrorismo que más debe preocuparnos es el de tipo yihadista, como se afirma en el Informe Elcano sobre Política Exterior de España: "La potencial inestabilidad de su vecindario sur, de donde provienen gran parte de las amenazas a la seguridad: radicalismo, terrorismo, suministro energético, tensiones demográficas y conflictos territoriales no resueltos" 39 .

Este tipo de terrorismo comparte algunas características con el que se acaba de mencionar de ETA, pero tiene una serie de particularidades que le hace más difícil de controlar: su raíz ideológica, el idioma en el que se comunican habitualmente sus miembros, su internacionalización o capacidad de actuar de manera global en todas las facetas de su labor -captación de fondos, tareas de reclutamiento, de adoctrinamiento y de entrenamiento, compra de material bélico, apoyo logístico, red de pisos francos, etc-.

Este es un terrorismo exógeno, originado fuera de nuestras fronteras, nacido en territorios que escapan al imperio de la Ley -al menos de lo que Occidente entiende por Ley-. Este fenómeno también crece en un ambiente propicio, generalmente en Estados fallidos o alentado por Estados gamberros. La ESN/2013 señala, además, que España siempre ha sido objetivo de los yihadistas ya que toda la Península Hispánica fue tierra del Islam -dar al Islam - y, según la doctrina islamista más extendida, todo territorio que alguna vez estuvo bajo dominio musulmán debe ser restituido a dicho dominio.

A la vista de semejante objetivo, carece prácticamente de importancia el nombre que recibe el grupo que esté detrás de cada acto terrorista concreto. Si es Al Qaeda o es Al Qaeda en el Magreb Islámico (AQMI), tanto si es un grupo subcontratado por ellos, o si primero realizan el acto terrorista y luego negocian con AQMI su afiliación, el hecho cierto es que estos grupos poseen una ideología semejante y no tienen reparos en aliarse para conseguir sus objetivos comunes, como tampoco tiene reparos en separase o debilitar su estructura por cuestiones personales, de liderazgo o incluso de financiación. De manera que casi todo el terrorismo que afecta a la UE proviene de Al Qaeda o de grupos que están ligados de alguna manera ella -sea en los países del norte de África o en Asia Meridional— ${ }^{40}$. Como afirmó el

\footnotetext{
llamativo que en Melilla, la otra ciudad española incrustada en la costa norteafricana, no ha habido ni un solo caso de aspirante a yihadista que haya viajado a Siria. Las fuerzas de seguridad achacan ante todo el fenómeno ceutí al entorno marroquí. En las vecinas aglomeraciones urbanas de Castillejos y Tetuán existen redes salafistas que captan, sobre todo, a marroquíes pero también a jóvenes musulmanes españoles. El predicador radical Omar Hadouchi, excarcelado en 2011, ejerce una gran influencia sobre los jóvenes tetuaníes”. Ver Cembrero, Ignacio: "Nueve ceutíes se han marchado a Siria a hacer la yihad en solo un año", El País, 21 de Mayo de 2013, en http://politica.elpais.com/politica/2013/05/21/actualidad/1369149235 171974.html.

${ }^{39}$ Ver: Molina, Ignacio: "Hacia una renovación estratégica de la política exterior española", Informe Elcano, $\mathrm{n}^{\circ}$ 15 (Febrero 2014), p. 41.

${ }^{40}$ Aunque en un primer momento se pensó que Hezbolá estaba detrás del atentado terrorista del aeropuerto de Burgas (Bulgaria), perpetrado el 18 de julio de 2012, las posteriores investigaciones dieron evidencias de que los terroristas suicidas pertenecían a Al Qaeda. Ver: Porter, Gareth: "Bulgarian Revelations Explode Hezbollah Bombing "Hypothesis"”, Inter Press Service, 18 Febrero 2013, en http://www.ipsnews.net/2013/02/bulgarianrevelations-explode-hezbollah-bombing-hypothesis. Por su parte, la investigación israelí sigue fijándose en la pista de Hezbolá; ver Weinthal, Benjamin: "Bulgaria, Israel mark Burgas terror attack anniversary", Jerusalem
} 
senador por Oklahoma James M. Inhofe ante el Comité SASC del Senado de los EE.UU., aunque parezca que Al Qaeda está debilitada, dicho grupo terrorista sigue siendo una amenaza real para EE.UU., y por extensión de todo país occidental o que sea aliado de EE.UU.:

"[...] Al-Qaeda has evolved over the last decade. They're no longer confined to the mountains of Afghanistan and Pakistan. Instead, they now operate in more countries and control more territory than ever before. The increasingly decentralized nature of their network doesn't mean they're less dangerous. On the contrary, it means that Al-Qaeda poses an even greater threat to American lives and interests around the world ${ }^{41 " .}$

Según James R. Clapper, el Director Nacional de Inteligencia, Al Qaeda estaría aguardando el momento de la retirada de tropas de la ISAF de Afganistán para reactivarse ${ }^{42}$.

Otra cosa distinta es que algunos grupos que dicen ser terroristas o actuar en nombre de Al Qaeda luego resultan ser meros delincuentes, dedicados a traficar con lo que sea -armas, drogas, personas- con un fin específicamente crematístico, no político, ideológico o religioso.

Aunque las Fuerzas Armadas de España participan en misiones de entrenamiento antiterroristas en países subsaharianos, el terrorismo yihadista que más debe preocupar a las autoridades españolas es el que se origina dentro de las propias fronteras -especialmente en las ciudades autónomas de Ceuta y Melilla y en la comunidad catalana-. Ahí el trabajo le corresponde en gran medida a los distintos cuerpos policiales -Policía Nacional, Guardia Civil, Policías autonómicas y $\mathrm{CNI}^{43}$ - y a los jueces ${ }^{44}$.

\subsubsection{Los procesos de radicalización}

En las últimas décadas se ha prestado mucha atención en el ámbito académico y en el de la lucha contra el terrorismo a los procesos de radicalización, que explicarían por qué una persona pasaría de tener una ideología dada a empezar a cometer actos violentos fuera de la legitimidad del Estado. Se ha abusado -hay que reconocer que más en los medios de comunicación - del término "fundamentalismo", que nació precisamente para referirse a unos grupos cristianos de comienzos del siglo XX en EE.UU. ${ }^{45}$. El término más apropiado es el de "yihadismo", que es la ideología que pretendería dar cobertura a la lucha armada desde una motivación (pseudo-)religiosa.

Post, 19 Julio 2013, en http://www.jpost.com/International/Bulgaria-Israel-mark-Burgas-terror-attackanniversary-320356, accedido el 15 de enero de 2014.

41 Ver Inhofe, James M.: "Senate Armed Services Committee Hearing on Current and Future Worldwide Threats", US Senate (11 de febrero de 2014), en http://www.inhofe.senate.gov/newsroom/press-releases/inhofeopening-statement-at-senate-armed-services-committee-hearing-on-current-and-future-worldwide-threats-.

${ }^{42}$ Ver Clapper, James R.: "Statement for the record Worldwide Threat Assessment of the US Intelligence Community", en https://www.hsdl.org/?view\&did=749636.

${ }^{43}$ Este órgano ha demostrado ser bastante eficaz en su lucha contra el terrorismo pues se ha visto cómo el número de atentados perpetrados desde entonces se ha disminuido drásticamente, especialmente los que causaran víctimas mortales.

44 "En particular, se deberá fortalecer la colaboración con la UE, países vecinos y EEUU en la lucha contra el terrorismo, el crimen organizado y la inmigración irregular"; ver Molina, Ignacio: "Hacia una renovación estratégica de la política exterior española", Informe Elcano, no 15 (Febrero 2014), p. 55.

${ }^{45}$ Ver: Petschen Verdaguer, Santiago: "El fundamentalismo protestante", en Corral Salvador, Carlos (ed.) (1994): Los fundamentalismos religiosos, hoy, en las Relaciones Internacionales, Madrid, UPCO, p. 83. 
Estos procesos de radicalización tienen unos orígenes muy diversos. Algunos investigadores apuntan a causas económicas como causa principal de dio proceso. Otros señalan causas políticas. Otros, de orden social o incluso familiares. Otros se fijan más en las psicológicas. Parece que lo más acertado sería hacer un análisis multifactorial que no atribuyera a un solo origen la causa por la que una persona da el salto a la violencia. En distintos países de nuestro entorno -Gran Bretaña ${ }^{46}$, Holanda ${ }^{47}$, entre otros- se han realizado estudios públicos y privados para intentar esclarecer estos extremos, sin olvidar la aportación de autores especializados como Oliver Roy ${ }^{48}$ o Fernando Reinares ${ }^{49}$ o Javier Jordán ${ }^{50}$.

Esta radicalización se lleva a cabo en España, principalmente, en las mezquitas donde acuden inmigrantes procedentes Asia Meridional o del Magreb. Aquí, la cuestión fundamental radica en manos de qué imanes caen estas personas, ya que les pueden guiar por el camino del Islam verdadero o llevarles por derroteros de un Islam falseado y viciado que les conduce a realizar actos de violencia, como el caso de los yihadistas reclutados en Ceuta o Melilla que han viajado a luchar a Siria ${ }^{51}$. El dilema y la preocupación para el Ministerio del Interior de España está en que no pueden ejercer un control absoluto sobre cada uno de los predicadores que pululan por España y, por tanto, necesitan fiarse de alguna rama del Islam que sea, por lo menos, de las más abiertas y tolerantes; en resumidas cuentas, no saben si fiarse de los marroquíes o de los saudíes.

\footnotetext{
${ }^{46}$ Ver los estudios de la Quilliam Foundation, especialmente el libro de uno de sus fundadores, Husain, (ed.) (2007): The Islamist, Londres, Penguin; ver también los trabajos de algunos periodistas, como O’Neill, Sean y McGrory, Daniel (2006): The Suicide Factory: Abu Hamza and the Finsbury Park Mosque, Londres/Nueva York/Tokio/Sídney, Harper Perennial.

${ }^{47}$ El informe de noviembre de 2013 realizado por el Coordinador Nacional de Seguridad y Antiterrorismo del Ministerio de Seguridad y Justicia de Holanda, mantenía alto el nivel de alerta debido a que la situación en Siria había empeorado: "The present threat assessment is still mainly determined by the involvement of foreign combatants in the Syrian conflict. There are also worrying indications of growing radicalisation among small groups of young Muslims in the Netherlands"; Ver: Summary of the 34th edition of the Terrorist Threat Assessment for the Netherlands (DTN34), 7 de noviembre de 2013, en

http://english.nctv.nl/currenttopics/press_releases/2013/press-release-dtn34.aspx; ver Veldhuis, Tinka y Staun, Jørgen: "Islamist Radicalisation: A Root Cause Model", Netherlands Institute of International Relations Clingendael (Octubre 2009); ver también los análisis del Servicio General de Inteligencia y Seguridad de Holanda (AIVD), especialmente "Local Jihadist Networks In The Netherlands: An Evolving Threat", 2010, en https://www.aivd.nl/english/publications-press/aivd-publications/@1583/local-jihadist, accedido el 10 de enero de 2014.

${ }^{48}$ Ver, entre otros, Roy, Oliver: "Islamic terrorist radicalisation in Europe", en Amghar, Samir Boubekeur, Amel y Emerson, Michael (ed.) (2007): European Islam. Challenges for public policy and society, Bruselas, Centre for European Policy Studies.

${ }^{49}$ Ver, sobre todo, Reinares, Fernando (2003): Terrorismo global, Madrid, Taurus; ver también García-Calvo, Carola y Reinares, Fernando: "Procesos de radicalización violenta y terrorismo yihadista en España: ¿cuándo? ¿dónde? ¿cómo?”, Documento de Trabajo Elcano, n 16 (Noviembre 2013), en

http://www.realinstitutoelcano.org/wps/wcm/connect/a6b75f8041dfd3d9bf9effc7c0642f11/DT16-

2013 Reinares-

GcaCalvo_radicalizacion terrorismo yihadista espana.pdf?MOD=AJPERES\&CACHEID=a6b75f8041dfd3d9b f9effc7c0642f11.

50 Ver Jordán, Javier: "El terrorismo yihadista en España", Jihad Monitor, marzo de 2005, en http://www.ugr.es/ terris/Terrorismo\%20islamista\%20en\%20Espana.pdf.

51 Ver: Reinares, Fernando y García-Calvo, Carola: "Yihadistas en Siria procedentes de España: hechos y cifras", Comentario Elcano, 79/2013 (18 Diciembre 2013), en

http://www.realinstitutoelcano.org/wps/portal/rielcano/contenido?WCM_GLOBAL_CONTEXT=/elcano/elcano _es/zonas_es/reinares-garcia-calvo-yihadistas-siria-procedentes-espana. Si estos investigadores cifraban en 17 los españoles que habían marchado a Siria hasta finales de 2013, la Policía Nacional detuvo el 5 de enero en Málaga al ceutí Abdeluahid Sadik Mohamed; por tanto, se puede añadir uno más a esa lista, y parece que no será el último; ver: "El CNI contactó con Al Asad para recabar datos de yihadistas españoles", La Voz de Galicia, 16 Enero 2014, en http://www.lavozdegalicia.es/noticia/internacional/2014/01/16/cni-contacto-asad-recabar-datosyihadistas-espanoles/0003 201401G16P24991.htm.
} 
Otro punto de captación de nuevos terroristas en España se lleva a cabo en las cárceles. Si bien es cierto que este asunto lo han sabido gestionar con astucia desde Instituciones Penitenciarias y han sabido aislar a los que ya son terroristas o están más radicalizados de los presos comunes que son musulmanes, eso no evita para que hayan puesto en práctica su maquinaria de reclutamiento en algunas cárceles europeas. El mecanismo es bien sencillo: ,mientras en el cristianismo parece que hay bastante fluidez entre los sentimientos de culpa y perdón -si uno peca y se siente mal, sabe que el sacrifico de Cristo en la cruz fue una vez y para siempre y puede acudir a un sacerdote para que éste le perdone en nombre de Cristo sus pecados, en el caso de los católicos, o puede ponerse a bien interiormente, en el caso de algunos protestantes-, en el Islam no sucede así sino que se puede llegar a una situación de estancamiento, siendo la única posibilidad de redención y evitar así el castigo eterno -y recibir de paso una buena recompensa en el más allá- el salto a los actos de martirio, que garantizan un pase directo al paraíso.

En otros sitios de Europa, donde hay una tradición de inmigración musulmana más extensa en el tiempo y en la cantidad, y estos o sus hijos ya han llegado a la universidad, la radicalización se da a través de la educación y de algunos libros de texto ${ }^{52}$ y el reclutamiento puede darse en los campus universitarios -como es el caso del Reino Unido-. Se abriría aquí un buen debate sobre los distintos modelos de integración de la comunidad inmigrante en los diversos países europeos, sobre cuál ha sido más eficaz, qué país ha sabido absorber mejor las diferencias y asimilar y acoger a los que venían de fuera y les han hecho sentirse como en casa,... pero tal debate excede los límites de este capítulo.

Estos grupos yihadistas saben, además, emplear de manera extraordinaria la propaganda para alcanzar sus fines. Lo hacen usando todos los medios que estén a su alcance, según las épocas: libros, folletos, periódicos, revistas, cintas de audio o video, DVD, .. y por último Internet. Este último medio es el más utilizado, pues su interés es reclutar a gente joven y desencantada con Occidente, sensibilizarles hacia los problemas del resto de musulmanes de otros países, que viven en peores condiciones que ellos, señalando siempre al mismo culpable (Occidente, EE.UU., sus aliados, Israel, o los sátrapas sostenidos por EE.UU.). Se habla, también, del deseo de algunos grupos de llevar a cabo una ciberyihad ${ }^{53}$.

\subsubsection{Obietivo: recuperar al-Ándalus}

Queda claro que si entre sus aspiraciones máximas los grupos yihadistas desean reconquistar al-Ándalus, el objetivo de estos grupos ha de ser "subvertir el orden constitucional o alterar gravemente la paz pública", convirtiéndose por tanto en grupo terrorista -siempre y cuando recurran medios violentos, claro está-.

Al-Ándalus ha estado presente en el imaginario colectivo de los islamistas desde la misma pérdida definitiva con la caída de Granada en 1492 a manos de los Reyes Católicos y

\footnotetext{
${ }^{52}$ En España, la Fundación Pluralismo y Convivencia, dependiente del Ministerio de Justicia, ha hecho un trabajo de elaboción de libros de texto de la asignatura de religión musulmana para los tramos del sistema educativo donde esta sea obligatoria. Esto no se ha podido realizar en otros países europeos, como por ejemplo en Alemania, donde la injerencia del Estado en tal asunto ha sido considerado siempre una pura intromisión.

53 "A significant proportion of the frustrated plots to attack Western targets in the last four years feature a prominent virtual component. With the publication of "Jihadism on the Web, A breeding ground for Jihad in the modern age" in 2012, the AIVD explains how the Internet is used by jihadists. Furthermore, jihadist terrorism includes the intention of conducting a cyber jihad in which digital tools can be deployed against opponents of Islam. The AIVD currently estimates the jihadist movement's potential in digital terms as being limited"; Ver el Informe "Annual Report 2012" del Servicio General de Inteligencia y Seguridad de Holanda, en https://www.aivd.nl/english.
} 
el fin definitivo de la Reconquista ${ }^{54}$. Más aún, si cabe, este ha sido un objetivo prioritario desde que en el siglo XX el fin del colonialismo vino precedido y acompañado por todo un movimiento intelectual que preconizaba la independencia de tales territorios coloniales contra las potencias occidentales. Desde ese momento, la imagen de la recuperación de al-Ándalus ha motivado a los más diversos grupos terroristas, por muy alejados que estén de nuestro suelo patrio, por mucho que jamás hayan pisado este terreno. Dicha imagen es casi tan poderosa como la recuperación de $A l-Q u d s$-Jerusalén-, el fin del enfrentamiento entre israelíes y palestinos, imagen que ha sido usada en reiteradas ocasiones como fuente de victimismo, así como lo han sido otros conflictos protagonizados por Occidente, como las guerras balcánicas o las campañas en Afganistán o Irak. La maquinaria propagandística de los grupos yihadistas y de los que le siguen el juego ha incidido en estos puntos a través de cintas de video, CDs, DVDs y, en los últimos años, a través de la red (websites, foros y redes sociales).

Dicha propaganda, así como las distintas estrategias de captación de nuevos adeptos, han sido estudiadas por expertos pero también por los miembros de las Fuerzas y Cuerpos de Seguridad españoles. Como es lógico, se sigue un proceso particular con aquellos acerca de los que se tienen fundadas sospechas de estar relacionados con estos ambientes yihadistas o que, directamente, han caído en sus redes o hacen de captadores de otros incautos. Así, en primer lugar, los sospechosos son investigados por el CNI; una vez se hayan obtenido indicios de criminalidad, se pasa ese caso a la Policía/Guardia Civil; una vez se han obtenido indicios suficientes, lo pasan al juzgado para que sea una investigación judicial quien pruebe si son o no culpables de delito de terrorismo. Así, en España ha habido una veintena de casos contra terrorismo yihadista en los últimos 30 años, especialmente a partir del 11-S, que es cuando se empezó a prestar atención a este tipo de terrorismo en España, y mucho más a partir del 11-M, como ya se ha señalado anteriormente ${ }^{55}$. Algunas de las operaciones judiciales más famosas son "Espiral”, "Vórtex”, "Nova”, "Dátil”, “Tigris".

Esa evocación a Al-Ándalus es tan poderosa que España no ha cesado de ser un lugar de reclutamiento de yihadistas ${ }^{56}$, incluso provenientes de otros países -Marruecos y Francia, entre otros - que después han ido a luchar -como muyahidines - a Afganistán, Irak, Pakistán, Libia o Siria ${ }^{57}$.

\footnotetext{
${ }^{54}$ Ver Arístegui, Gustavo (2005): La yihad en España: La obsesión por reconquistar Al-Andalus, Madrid, La Esfera de los Libros.

55 "Informe tras informe, tanto el Centro Nacional de Inteligencia (CNI) como la Policía Nacional y la Guardia Civil no se cansan de insistir en que el riesgo sigue presente. Entre otros elementos, constatan que España es una "base durmiente" de radicales, como se puede comprobar con la guerra civil de Siria. Según los informes que obran en poder de este periódico, en los últimos meses un centenar de yihadistas asentados en España se han trasladado al país de Oriente Próximo vía Marruecos. Según los informes de los servicios de inteligencia, desde finales del pasado año han abandonado España una media de 30 islamistas radicales al mes. En muchos casos han viajado junto a sus mujeres e hijos"; Ver: Lázaro, Fernando: "Cien 'yihadistas' residentes en España se han trasladado a Siria”, El Mundo, 11 de marzo de 2014, en http://www.elmundo.es/espana/2014/03/11/531e697b22601dac6f8b457a.html.

${ }^{56}$ Ver los documentos del Real Instituto Elcano sobre esta cuestión en: http://www.realinstitutoelcano.org/wps/portal/rielcano/TerrorismoInternacional.

57 Es muy instructivo estudiar las biografías y la investigación policial de los residentes en las ciudades autónomas que han viajado a lugares de combate a luchar por el Islam, como fueron Rachid, Tafo y Piti. Ver: Irujo, José María: "Muere otro yihadista ceutí en Siria", El País, 18 Julio 2012, en http://politica.elpais.com/politica/2012/07/17/actualidad/1342559055 659472.html. Ver también del mismo autor: "La red islamista desarticulada envió a "decenas" de muyahidines a Siria y Libia", El País, 14 de marzo de 2014, en

http://politica.elpais.com/politica/2014/03/14/actualidad/1394781849_681744.html.
} 
La pregunta que surge aquí es cómo las Fuerzas y Cuerpos de Seguridad españoles logran interceptar y desarticular estas células, si lo hacen de manera preventiva o de manera reactiva. Al hilo de las últimas operaciones en Ceuta y Melilla, se ha podido constatar que hay todo un trabajo de seguimiento de ciertas personas antes de que cometan un atentado y que hay un seguimiento de otros sujetos que ya han cometido actos terroristas -principalmente fuera de nuestras fronteras-. Así, la información compartida por otros países con nuestras autoridades se revela como fundamental ya que por un lado se pone en seguimiento a ciertos sospechosos - ex antea - y por otro se informa de la "trazabilidad", del itinerario que ha llevado una persona hasta caer preso o muerto en operaciones en los escenarios de combate ya mencionados - ex post - Sea antes o después, la cooperación internacional se ha manifestado, como se acaba de decir, esencial, incluso con países que no compartan nuestros valores democráticos -como dice explícitamente la Estrategia británica de seguridad ${ }^{58}$ -

Aparte del reclutamiento, hay que evitar el entrenamiento, pues si no mueren en los lugares de combate adquieren una experiencia y un aura de legitimidad muy estimable desde su punto de vista y se convierten en héroes o líderes -o ambas cosas a la vez- con posibilidad de poner en práctica sus conocimientos ${ }^{59}$.

Además, no hay que perder de vista que en España toda acción de la lucha antiterrorista debe ser judicializada, es decir, ya que el objetivo último de la lucha antiterrorista no es eliminar al sujeto sino juzgarle y hacer que cumpla condena por sus actos, se deben observar una serie de protocolos que otorgue al sospechoso ciertas garantías procesales, entre otras cosas para que en nuestro Estado de Derecho la investigación o el resto de las actuaciones policiales puedan surtir los efectos deseados y no sea declarado nulo todo el proceso. Por lo tanto, toda vez que se pone en seguimiento a una persona debe ser con conocimiento de un juez, lo que a la vez complica un poco más la lucha terrorista pero también le da una serie de garantías.

\subsubsection{La financiación del terrorismo yihadista}

El terrorismo yihadista es muy permeable y se adapta a toda circunstancia política, económica o social y aprovechan la inestabilidad en ciertas áreas geográficas para reclutar o entrenar gente o bien para recaudar fondos. Sin embargo, se puede decir que el terrorismo yihadista es pobre ya que apenas necesita dinero para causar los estragos que ocasiona. Se calcula que, por ejemplo, el 11-M costó alrededor de 47.000€, pues la logística que necesitan es mínima, y en ocasiones el dinero físico ni siquiera aparece pues se cambia drogas por explosivos, por ejemplo.

En este punto, es necesario distinguir entre microfinanciación y macrofinanciación. Mientras la microfinanciación es el dinero que se desea obtener para cometer un acto terrorista concreto, la macrofinanciación es la recaudación necesaria para mantener todo el entramado logístico permanente, la estructura, del grupo terrorista. La microfinanciación suele

\footnotetext{
58 "Protecting our security requires us to work with countries who do not share our values and standards of criminal justice. In working with them to protect our country from terrorist attacks and other threats we do not compromise on our values. We speak out against abuses and use our own conduct as an example. But we have to strike a balance between public condemnation of any deviation from our values and the need to protect our security through international cooperation". Ver "A Strong Britain in an Age of Uncertainty: The National Security Strategy", op. cit., p. 23.

${ }^{59}$ Ver: Swinford, Steven: "Return of 250 British jihadis from Syria 'serious threat', says minister", The Daily Telegraph, 16 Febrero 2014, en http://www.telegraph.co.uk/news/uknews/terrorism-in-the-uk/10642674/Returnof-250-British-jihadis-from-Syria-serious-threat-says-minister.html; Ver también el caso de Abu Hamza expuesto en O’Neill y McGrory, op. cit.
} 
realizarse a través de pequeños robos y, sobre todo, a través del tráfico de drogas (hachís de Marruecos, heroína de Pakistán,...). Por ejemplo, la "Operación Nova", que planeaba hacer saltar por los aires la Audiencia Nacional con $500 \mathrm{~kg}$ de explosivos y que tuvo su origen en la cárcel de Topas (Salamanca), sólo necesitaban 10.000€ para que un oriundo de Almería se los consiguiera.

Por otro lado, la macrofinanciación es algo más compleja. Se suele realizar a través de la limosna (zakat) que todo buen musulmán debe dar. Ese dinero se suele utilizar para el mantenimiento de páginas web y para financiar los viajes de militantes a campos de entrenamiento $^{60}$ (en ocasiones, en lugares de conflicto). Aquí es fundamental la hawala (transferencia informal de fondos), que es un sistema de compensación basado en la confianza recíproca en el que en ocasiones no hace falta siquiera operar con dinero real sino que se hace con la palabra dada, con promesas, o bien a través de una especie de "cheques" o de dinero virtual. En Internet no hay nombres, no hay IP -menos aún si se utilizan los cibercafés-, es anónimo, sólo hay máscaras.

Las tarjetas "cash- $U$ " son otra vía de financiación. Cada una de estas tarjetas tiene un código y pueden ser recargadas con la cantidad de dinero que se desee. Todo ese dinero va a una cuenta común que se indique y, como se acaba de señalar, todo esto se hace con el máximo anonimato y, por tanto, es muy difícil seguirle el rastro. Se ha comprobado que los grupos que operan así en España reciben dinero a través de este sistema de personas que viven en Arabia Saudita, Yemen, Turquía, Argelia, Somalia, Chechenia o Pakistán.

La Ley 10/2010 sobre el blanqueo de capitales (que reforma la Ley 12/2003), amplía el número de "sujetos obligados" a establecer medidas de seguimiento para evitar estos movimientos de capitales. Se trata, principalmente, de las cajas de ahorro, bancos, despachos de abogados,... Si incumplen sus obligaciones y facilitan la financiación de grupos terroristas a través de sus redes de sucursales, cometen un delito de financiación de terrorismo. Deben estar vigilantes, tienen la obligación de saber quién es su cliente y de dónde viene y a dónde va ese dinero. El "caso Falciani", que destapó la negligencia del banco HSBC a la hora de evitar el blanqueo de dinero, ha sido clave para asentar la doctrina expuesta en esa Ley $10 / 2010$.

\subsection{Los "lobos solitarios"}

El Código Penal español concreta en la Sección Segunda del Capítulo VII (arts. 572-580) cuáles son considerados "delitos de terrorismo". La clave de lectura de estos artículos es, sin embargo, siempre colectiva, organizacional, atendiendo por tanto a una estructura estable, nunca relacionado con la estructura típica de los grupos terroristas islamistas, que suele ser mucho más difusa ${ }^{61}$, más centrada en el objetivo final, que es muy vago y genérico -golpear a Occidente siempre que sea posible y de la forma que sea posible, según reza la fatwa que Osama Bin Laden decretó en agosto de 1996 y que lleva por título "Declaración de guerra contra los americanos que ocupan la tierra de los dos santos lugares"-. El terrorismo islamista funciona más sobre la base de la confianza mutua y, más importante aún, de la subordinación de todos con respecto a un fin superior que les sobrepasa, incluido al líder del

\footnotetext{
${ }^{60}$ Ver: Alonso, Antonio: "El dilema de la tolerancia con los "tablighi"”, GEES, 30 de septiembre de 2013, en http://www.gees.org/articulos/el_dilema_de_la tolerancia_con_los \%E2\%80\%9Ctablighi\%E2\%80\%9D_9835, accedido el 10 de octubre de 2013.

${ }^{61}$ Ver Gunaratna, Rohan (2003): Al Qaeda: Viaje al interior del terrorismo islamista. Barcelona, Servidoc.
} 
momento; en resumen, es más importante la causa que el líder, los subordinados o que el propio grupo $^{62}$.

No obstante, estos artículos se suelen interpretar de manera más amplia para incluir también a estos grupos que, si bien funcionan de manera distinta al terrorismo que tradicionalmente ha azotado España, no es menos peligroso. Su funcionamiento obedece a una compleja división internacional del trabajo donde unas personas -que pueden constituir una célula o formar parte de un grupo, con marca o sin ella- se dedican a la recaudación de dinero, otras a radicalizar jóvenes, otras a captar muyahidines, otras a proveerles de entrenamiento, armas, munición, apoyo logístico,... y así un largo etcétera. De esta manera, cada "grupo" se especializa en una función específica, usando una marca o no para ello. De ahí que el Código Penal hable vagamente de "más de dos personas con carácter estable o por tiempo indefinido".

Estamos, así, ante dos niveles distintos de organización: uno más general, más superficial, y otro más específico, más fragmentado. El Código Penal no sería eficaz contra el primero pero sí para el segundo tipo. De esta manera se afrontaría el problema pieza a pieza, paso a paso. Una forma, quizás, eficaz de luchar contra este terrorismo.

Sin embargo, ¿será igual de eficaz frente a los denominados "lobos solitarios"? Parece que no hay lucha contra el terrorismo individual, que debe ser contra grupos terroristas. Sin embargo, también parece evidente que, a pesar de su nombre, no son tan solitarios como dicen ser. Especialmente porque participan de una ideología mucho más amplia y elaborada que no proviene de ellos mismos sino que ha sido aprendida. En ningún caso de los tratados por los medios de comunicación social como "lobos solitarios" se puede hablar de tal soledad absoluta. Sea Breivik, Merah, los terroristas de la maratón de Boston ${ }^{63}$ o los de Woolwich ${ }^{64}$, estos "lobos" se radicalizaron a través de otros canales, fueran las redes sociales, webs, foros o por la participación en reuniones de otros grupos poco aconsejables. O se acepta que estos terroristas no son solitarios, o se acepta que no son terroristas, según la definición del Código Penal, pues este no contempla el terrorismo en solitario, sino que lo rebaja a la categoría de simple criminal. Sin embargo, parece evidente que estas personas no buscan sólo matar gente sino que desean asesinar para conseguir otro tipo de objetivos, entre otros amedrentar a la población, sembrar el caos y la confusión y la sensación de inseguridad, objetivos estos que están lejos de ser los típicos de un criminal que actúa en solitario sino más bien los de un grupo terrorista.

\section{La cooperación internacional en ámbitos multilaterales}

La ESN/2013, como lo hacía su antecesora de 2011, reconocía el valor fundamental de la cooperación internacional para la lucha contra el terrorismo. Si cada vez es más evidente que en todos los campos de nuestra vida -economía, comercio, formación académica, investigación o incluso nuestras amistades- estamos más interconectados en un escenario

\footnotetext{
${ }^{62}$ Ver Arístegui, Gustavo (2004): El islamismo contra el Islam. Barcelona, Bruguera.

${ }^{63}$ La revista Inspire, que difunde y defiende las ideas de Al Qaeda, les dedicó el número posterior a los atentados.

${ }^{64}$ Ver Alonso, Antonio: “El asesinato de Woolwich y Hizb ut Tahrir al Islami: ¿cuál es la conexión?”, GEES, 26 de junio de 2013, en

http://www.gees.org/articulos/el_asesinato_de_woolwich_y_hizb_ut_tahrir_al_islami_cual_es_la_conexion_976 $\underline{6}$.
} 
global, la seguridad es un ámbito en que esto se palapa sin necesidad de mucha reflexión. En el caso del terrorismo se puede decir que los grupos terroristas le llevan una amplia ventaja a los Estados pues aquellos se mueven libremente sin tener en cuenta las fronteras y, además, cooperan entre ellos para evitar la acción de los Estados. Por eso, se hace cada vez más necesario que se dé una cooperación eficaz en ámbitos multilaterales para hacer frente a esta amenaza que no es nueva.

Otro instrumento eficaz en la lucha contra el terrorismo son las denominadas listas de grupos terroristas. La UE tiene una que coincide en gran medida con la elaborada por el Departamento de Estado de EE.UU. Siguiendo este modelo, los distintos países también han ilegalizado algunos grupos por ser terroristas. No se trata sólo de países de Europa Occidental, sino también países asiáticos o de la antigua Unión Soviética o de su órbita.

\subsection{ONU}

En el ámbito de Naciones Unidas, el Secretario General estableció en 2005 un Equipo Especial sobre la Ejecución de la Lucha contra el Terrorismo y en 2006 la Asamblea General aprobó una Estrategia Mundial contra el terrorismo, donde se acuerda un marco estratégico y operativo común para luchar contra el terrorismo.

Sin embargo, es bien conocido cuál es el ámbito habitual de actuación de la ONU: aprobar resoluciones pseudonormativas con la fe y la esperanza de que dichos escritos transformen la realidad mundial; en contadas ocasiones la ONU ha tomado una resolución que implique el uso de la fuerza y que lleve a un cambio real de actitud del ente al que reprende o reprueba o que es objeto de su repulsa. En el caso del terrorismo se podría decir que su mayor éxito ha sido hacer que se sienten en la misma mesa distintos Estados para ponerse de acuerdo en algunos puntos esenciales en esa lucha contra el terrorismo. Los éxitos, como se ve, han sido escasos -más allá de la elaboración de dieciocho instrumentos internacionales-, aunque han hecho avanzar a una buena mayoría de países en la dirección de criminalizar y perseguir con mayor ahínco las actividades terroristas, ejercer un mayor control sobre los flujos financieros para asegurarse de que no acaben nutriendo a estos grupos y potenciar el empleo de un instrumento legal tan eficaz en lucha antiterrorista como es la extradición.

A pesar de todo, como sucede en toda acción que suponga el uso de la fuerza, contar con el respaldo de la ONU supone un aldabonazo legitimador a la acción que desee emprender cualquier Estado, especialmente si es fuera de sus fronteras e implica el uso de las Fuerzas Armadas, como es el caso de Francia en Mali.

\subsection{OSCE}

Uno de estos ámbitos multilaterales a los que la ESN/2013 presta atención es la OSCE, a quien le pide aplicar medidas de creación de confianza entre sus miembros para tener más información fiable y más instrumentos para acabar con esta lacra. A la OSCE se le pide, además, por su especialización en la cuestión de la dimensión humana, que impuse entre sus miembros una educación basada en la tolerancia que evite el brote de focos de odio o discriminación por razones de etnia o religión.

La OSCE condena reiteradamente el uso del terrorismo y cuenta con una serie de instrumentos para luchar contra él, el principal de ellos la Unidad de Acción contra el Terrorismo, creada en 2002. Entre sus documentos más destacados están la Carta de la OSCE para la prevención y lucha contra el terrorismo, de diciembre de 2002, y la Decisión $n^{o} 1063$ 
marco consolidado de la OSCE para la lucha contra el terrorismo, de 7 de diciembre de 2012. Siendo la cesta de la dimensión humana la más desarrollada de la OSCE, el foco de atención de estos documentos se pone en las causas del terrorismo, en los orígenes del mismo, y no tanto en la persecución de los delincuentes:

Los Estados participantes de la OSCE están convencidos de que la lucha contra el terrorismo exige esfuerzos integrales y duraderos, para hacer frente a las manifestaciones del terrorismo y a los diversos factores sociales, económicos, políticos y de otro tipo que puedan propiciar condiciones en las que las organizaciones terroristas puedan reclutar seguidores $\mathrm{o}$ buscar apoyo ${ }^{65}$.

\subsection{OTAN}

Otra organización internacional que la ESN/2013 cita expresamente es la OTAN. Fue a raíz del 11-S cuando la OTAN empezó a tomar una serie de medidas contra el terrorismo, toda vez que si el actor más importante de la Alianza Atlántica -EE.UU.- sufre unos gravísimos ataques terroristas, esta cuestión pasa a ocupar el primer lugar de la agenda ${ }^{66}$, y así se sigue manteniendo: "Terrorism poses a direct threat to the security of the citizens of NATO countries, and to international stability and prosperity more broadly" ${ }^{\text {"67 }}$. Como organización de seguridad regional centrada en la defensa de los Estados miembros, los instrumentos que emplea son fundamentalmente militares. Así, una vez se puso en marcha la "lucha global contra el terrorismo" (GWoT), se desarrollaron las campañas de Afganistán y de Irak dentro de dicho marco. Además, se desarrolla una cooperación con otros países para entrenar a sus ejércitos en la lucha contra los grupos terroristas. Pero parece que EE.UU. ya no desea estar tan presente en la retaguardia del escenario europeo sino centrarse más en sus propios problemas y patios traseros (América del Sur y Asia Pacífico, además de Oriente Próximo, aunque en este último escenario parece que también están en retirada ${ }^{68}$.

La OTAN cuenta con una serie de instrumentos para luchar contra el terrorismo. Pone a disposición de los países miembros sus capacidades militares, para que sean desplegadas lejos de sus fronteras con el convencimiento de que en este mundo globalizado las amenazas a la seguridad y estabilidad de la Alianza se originan en el Sahel y en Afganistán-Pakistán. Así se ha reconocido en una buena cantidad de documentos como las NATO's policy guidelines on counter-terrorism. También, promueve el intercambio de opinión entre expertos paera profundizar en la amenaza terrorista. En resumen, como se afirma en el $\mathrm{n}^{\mathrm{o}} 19$ del Nuevo Concepto Estratégico de la OTAN adoptado en Lisboa en noviembre de 2010:

"We will ensure that NATO has the full range of capabilities necessary to deter and defend against any threat to the safety and security of our populations. Therefore, we will $[\ldots]$ enhance the capacity to detect and defend against international terrorism, including through enhanced analysis of the threat, more consultations with our partners, and the development of appropriate military capabilities, including to help train local forces to fight terrorism themselves."

\footnotetext{
${ }^{65}$ Ver: Decisión no 1063 marco consolidado de la OSCE para la lucha contra el terrorismo, $\mathrm{n}^{\mathrm{o}} 5$.

${ }^{66}$ Ver: de Mora-Figueroa, Dagmar: "Respuesta de la OTAN al terrorismo", en http://www.nato.int/docu/review/2005/issue3/spanish/art1.html.

${ }^{67}$ Ver el "Nuevo Concepto Estratégico de la OTAN", no 10.

${ }^{68} \mathrm{La}$ actitud dilatoria de los EE.UU. en el caso del derrocamiento de Gadafi en Libia (Res. ONU S/RES/1973 (2011) sirvió de muestra de cómo en adelante los problemas del vecindario europeo deberían ser gestionados por los europeos (S/RES/2085 (2012), que derivó en la Misión EUTM-Malí establecida por el Consejo en su Decisión 2013/34/CFSP). Ver: "balance de un año de misiones en el exterior", Revista Española de Defensa, $\mathrm{n}^{\circ}$ 302 , enero de 2014, p. 16.
} 
En ese escenario militar en el que se mueve la Alianza, la consideración con la que trata la amenaza terrorista no es desde el punto de vista policial sino de resolución de conflictos, al menos a tenor de lo que expresó en la Cumbre de Chicago sobre la situación de Afganistán:

"Today we have taken further important steps on the road to a stable and secure Afghanistan and to our goal of preventing Afghanistan from ever again becoming a safe haven for terrorists that threaten Afghanistan, the region, and the world. The irreversible transition of full security responsibility from the International Security Assistance Force (ISAF) to the Afghan National Security Forces (ANSF) is on track for completion by the end of 2014, as agreed at our Lisbon Summit. We also recognise in this context the importance of a comprehensive approach and continued improvements in governance and development, as well as a political process involving successful reconciliation and reintegration ${ }^{69} . "$

Como se puede observar, el terrorismo internacional ha pasado a ser el tótem, el elemento vertebrador de la Alianza, el motor principal para que esta exista, para aglutinar a sus miembros y para extender la cooperación de ésta con terceros países -incluido Rusia—; ya no es la protección frente al bloque ni el control del peligro de conflictos internos sino el terrorismo:

\begin{abstract}
"Terrorism in all its forms and manifestations can never be tolerated or justified. We deplore all loss of life from acts of terrorism and extend our sympathies to the victims. We reaffirm our commitment to fight terrorism with unwavering resolve in accordance with international law and the principles of the UN Charter. Today we have endorsed NATO's Policy Guidelines on Counter-Terrorism, and task the Council to prepare an Action Plan to further enhance NATO's ability to prevent, deter, and respond to terrorism by identifying initiatives to enhance our threat awareness, capabilities, and engagement ${ }^{70} . "$
\end{abstract}

A tal fin, la OTAN se fija unos límites, como el cumplimiento de toda normativa internacional y de todos los compromisos internacionales aplicables a este campo, que en general suelen velar por que se respeten los derechos humanos de los que son considerados terroristas y por el respeto de las normas de ius cogens ${ }^{71}$. También hay un esfuerzo considerable por coordinar mejor los esfuerzos multilaterales y evitar las duplicidades ${ }^{72}$. Sin embargo, a pesar de todos los esfuerzos - políticos y económicos- no parece que se esté ganando la lucha por los corazones y las mentes ${ }^{73}$, y menos utilizando ese tipo de medios.

\footnotetext{
${ }^{69}$ Ver "Chicago Summit Declaration", $n^{\circ} 5$.

${ }^{70}$ Ibid., $\mathrm{n}^{\mathrm{o}} 51$.

${ }^{71}$ El uso de drones en los ataques contra terroristas en suelo pakistaní no parece muy dentro de dicha legalidad internacional, como tampoco lo estuvo la operación contra Bin Laden. Aunque las Orientaciones de la OTAN no lo establezcan así, parece que en esta guerra contra el terrorismo todo vale, haciendo bueno no sólo el viejo dictum -en el amor y en la guerra todo vale - sino que además pone argumentos muy peligrosos en manos de los predicadores del odio antiyanki o antiimperialista - "política de doble rasero", "esta es su democracia", "esta es su idea de libertad",... afirman estos mientras se muestran fotos de cadáveres de niños caídos bajo ataques estadounidenses o de la OTAN. Ver "NATO's Policy Guidelines On Counter-Terrorism", nº 6.

${ }^{72}$ Ibid., $\mathrm{n}^{\circ} 7$.

${ }^{73}$ Ver Tisdall, Simon: "Afghan war logs: How the US is losing the battle for hearts and minds", The Guardian, 26 Julio 2010, en http://www.theguardian.com/world/2010/jul/26/us-battle-hearts-minds-afghanistan.
} 


\section{La ESN/2013 y las posibles soluciones}

La ESN/2013 afirma que "la efectividad del modelo español de gestión de la amenaza terrorista prestigia a nuestro país en el exterior y lo convierte en referente en la materia". En efecto, si se refiere a la lucha contra el terrorismo yihadista, nuestro país ha sido golpeado en pocas ocasiones y ha evitado grandes atentados a través de operaciones policiales bien conocidas como las ya mencionadas anteriormente. Pero, ¿cómo frenar este terrorismo islamista? ¿Dónde acudir a frenar esta plaga?

En primer lugar, hay que ser consciente de que esta lucha es a largo plazo y requiere una coherencia y una persistencia a lo largo del tiempo. Se trataría pues de una auténtica política de Estado, que no estuviera sujeta a los cambios inherentes a las democracias, esto es, a los cambios de color del Gobierno.

En segundo lugar, esta lucha debe establecerse en varios frentes. El más evidente, es la lucha policial para detener a aquellas personas que en la actualidad son terroristas, que integran algún comando o pertenecen a un grupo concreto, que ya han realizado atentados o están realizando tareas auxiliares en dichos grupos. Otro frente sería el de la financiación, que es muy complejo, tiene muchas ramificaciones y, generalmente, traspasa con total impunidad las fronteras nacionales.

En tercer lugar, hay que frenar el avance de las ideologías que fomentan el desprecio hacia los demás y que difunden este mensaje con un vocabulario violento y agresivo, tanto dentro como fuera de nuestras fronteras. Parece evidente que sin este factor, los jóvenes principal objetivo de los captadores de nuevos muyahidines - no se lanzarían a esta aventura temeraria de inmolarse y convertirse así en "mártires" si no fuera por todo un soporte ideológico - con cierto tinte religioso- que sostiene tal mensaje. Es preciso insistir en la idea de que el Islam auténtico no respalda ese tipo de acciones; pero también es necesario recordar que no existe una autoridad central que diga cuál es el "auténtico Islam" y que de muchas reuniones de alto nivel entre clérigos e imanes se ha esperado un pronunciamiento claro y contundente sobre este tema, pero en su lugar ha habido silencio ${ }^{74}$.

Por último, se hace necesario dejar sin argumentos a este tipo de ideólogos del odio, para lo cual hay que fomentar la paz y el desarrollo social y económico en las regiones de donde surgen estos terroristas. Es cierto que también surgen terroristas en países avanzados y opulentos como Gran Bretaña, Alemania o EE.UU., pero la pobreza -más bien la miseriaen la que están sumidos muchos países árabe-musulmanes es utilizada por la propaganda de estos grupos para reclutar nuevos combatientes, más si aún si esos países están en guerra. Tanto una causa como la otra, miseria o falta de paz, tienen un culpable fácil de encontrar para estos mensajeros del odio: Occidente, y dentro de este, EE.UU. es la principal referencia, la causa primera de todos sus males. Incluso la existencia de dictadores sátrapas y administraciones corruptas no se debe a razones culturales propias sino a las injerencias del “gran Satán”-EE.UU., según estos ideólogos-.

Según la ESN/2013, las líneas de acción que se marca son semejantes a las de la Estrategia de lucha contra el terrorismo de la UE, que siguen estos cuatro pilares: la prevención, la protección, la persecución y la preparación de la respuesta ${ }^{75}$. Son cuatro pilares

\footnotetext{
${ }^{74}$ Ver Sadaat, Saleha: “Afghan Ulema, Parties Condemn Pakistani Clerics on Suicide Stance”, Tolo News, 3 de marzo de 2013, en http://tolonews.com/en/afghanistan/9642-afghan-ulema-parties-condemn-pakistani-clericson-suicide-stance.

${ }^{75}$ Ver ESN/2013, p. 41.
} 
muy ambiciosos pero necesarios para mantener España libre de ataques terroristas, tal y como ha sucedido desde 2004, y no porque no se haya buscado atentar sino por la eficacia de las Fuerzas y Cuerpos de Seguridad del Estado. El grueso del trabajo lo vienen realizando en el primer pilar, muy relacionado con el tercero que, a su vez, sirve de elemento disuasorio frente al surgimiento de nuevos terroristas. Como se ha dicho anteriormente, el más difícil de conseguir es la protección de los objetivos sensibles y el control de las fronteras. La respuesta, por último, la centra en dos ámbitos: el de la acción policial y judicial contra los que hayan perpetrado ataques terroristas y el del apoyo político y de la sociedad civil a las víctimas de dichos ataques. España ha sufrido -lamentablemente- durante décadas el flagelo del terrorismo y alguna lección ha aprendido ${ }^{76}$.

\section{La aplicabilidad de los principios informadores de la ESN/2013 a la amenaza terrorista}

La ESN/2013 establece como sus principios informadores la unidad de acción, la anticipación y prevención, la eficiencia y sostenibilidad en el uso de recursos y la capacidad de resistencia y recuperación. Se puede decir, de manera general, que todos ellos son deseables e incluso exigibles a las autoridades.

La unidad de acción implica que el presidente del Gobierno tiene en sus manos la respuesta a esta amenaza concreta, no sólo en el ámbito de las capacidades el estado sino de toda la sociedad. Eso implicaría que el Presidente fuera una persona con carisma y liderazgo, algo que ha escaseado entre los inquilinos del Palacio de la Moncloa de manera general. Incluso en los momentos de mayor prueba, justo después de un atentado, uno de los elementos que más se han puesto en tela de juicio es la gestión del Gobierno, justo en un momento donde la crítica debería haberse rebajado al mínimo y donde se debería haber hecho gala de una meridiana unidad. Esto es también válido para la resiliencia o capacidad de resistencia y recuperación. Además, la unidad de acción no está pasando por los mejores momentos pues, aunque se han hecho esfuerzos considerables, que los distintos cuerpos policiales compartan sus bases de datos o incluso sus investigaciones en marcha o ya cerradas no es nada fácil por la cantidad de información extra que pudiera colarse entre los informes o porque supondría poner en peligro activos muy valiosos. Por último, en lo que se refiere a la unidad de acción, en los momentos actuales hay una amplia fractura social en lo que se refiere a las divergentes opiniones en torno a la cuestión de ETA - está derrotada o no, es necesario dejar que actúen Bildu y Sortu o no, etc-. La unidad es esencial también en la lucha contra el terrorismo yihadista, pero también contra el de extrema derecha o izquierda; son, precisamente, elementos marginales los que se convierten en terroristas que se han radicalizado y han descubierto en estos grupos o ideologías un amparo. Tales actos no deben tener cabida en una sociedad democrática y no pueden ser ni amparados ni justificados por una porción de la opinión pública.

\footnotetext{
${ }^{76}$ Caso distinto es el de la gestión del final de la violencia - en el caso concreto de ETA—, donde los sucesivos gobiernos no han sabido gestar un consenso generalizado en torno a la cuestión, dejando una opinión pública muy dividida al respecto. Otros modelos parecen haber sido más exitosos, como el final en Italia de las Brigate Rosse (1987), en Alemania de la Fracción del Ejército Rojo, más conocida como Baader-Meinhof (1998), o en Gran Bretaña el IRA (1997). Aunque algunos de sus miembros han continuado cometiendo atentados, el apoyo que reciben sus acciones violentas por una parte de la sociedad quedó completamente desactivado en los momentos que se han señalado.
} 
La anticipación y prevención es, en el caso del terrorismo, un asunto de vital importancia. Hay que reconocer que, hasta la fecha, las autoridades españolas han sabido responder a tiempo, anticiparse a la amenaza terrorista, siendo en contadas ocasiones las que han conseguido sus objetivos, al menos en los últimos diez años.

En cuanto a la eficiencia, se hace necesario, en efecto, una mejor economía de los recursos que permita no duplicar esfuerzos y favorecer una cooperación cada vez más fluida y fructífera.

\section{Conclusiones}

El problema del terrorismo ha sido, es y será en los próximos años una amenaza para España. ETA mató por última vez en España en 2009 y a partir de ese momento todos los esfuerzos de las Fuerzas y Cuerpos de Seguridad españoles se han centrado en el control y persecución de otro tipo de terrorismo: el de los yihadistas. Aunque haya habido ataques perpetrados por pequeños grupúsculos derivados de los GRAPO o del anarquismo, la amenaza más acuciante proviene de estos grupos yihadistas que, aunque tienen su origen fuera de nuestras fronteras, utilizan España como lugar para descansar, recaudar fondos, captar nuevos adeptos y otras muchas actividades más.

España ha puesto en marcha una serie de instrumentos que ayudan a luchar más eficazmente contra el terrorismo. Sin embargo, queda todavía un camino largo por recorrer, atendiendo especialmente a sus fuentes de financiación y a la diseminación de su ideología que, inevitablemente, conduce al odio contra Occidente e incita a la recuperación de alÁndalus -es decir, de toda la Península Hispánica-.

Por último, como se ha dicho anteriormente, la estrategia más eficaz para erradicar el terrorismo es dejar al grupo terrorista sin base social, impidiendo que una simple banda de delincuentes se transforme en -o sea considerado- el brazo armado de una lucha política más amplia y general. Aislar a los terroristas de las personas que podrían constituir su sustrato, su apoyo, es lo más eficaz a largo plazo. Por otro lado, a corto y medio plazo se hace necesario incrementar la tarea de prevención y anticipación, utilizando principalmente medios policiales $\mathrm{y}$, sobre todo, de inteligencia -de señales, de imágenes,... pero sobre todo de inteligencia humana, esto es, infiltrados-, evitando al máximo el uso de medios militares, que están pensados para obtener ventajas tácticas en un enfrentamiento simétrico.

Así pues, para concluir, se puede decir que la Estrategia de 2013 acierta en muchos aspectos en lo tocante a la lucha contra el terrorismo, aunque deja en el aire algunas cuestiones -a la espera de la aprobación del resto de subestrategias, especialmente la de terrorismo y la de radicalización - y apuesta al $100 \%$ por la tesis de que ETA está derrotada, desprotegiéndose ante un eventual ataque terrorista en nombre de la banda criminal. 